\title{
Estudio, conservación y montaje de dos tobilleras de cascabeles provenientes del sitio arqueológico Teteles de Santo Nombre, Puebla
}

\author{
Fabiana González Portoni \\ Diana Medellín Martínez \\ Hilda Patricia Salgado Serafín
}

\section{Introducción}

\begin{abstract}
- I presente reporte tiene como finalidad exponer los procesos de estudio, - análisis, interpretación, conservación, restauración y montaje realizados a - 69 cascabeles metálicos de origen prehispánico asociados con restos de materiales orgánicos diversos: fibras textiles, fibras duras, piel y papel, que conforman dos tobilleras pertenecientes a un complejo funerario descubierto en el sitio arqueológico Teteles de Santo Nombre, en Puebla, México. El equipo del proyecto arqueológico homónimo, de la Dirección de Estudios Arqueológicos (DEA) del Instituto Nacional de Antropología e Historia (INAH), dirigido por el doctor Blas Román Castellón y complementado con la intervención de restauradoras de la Coordinación Nacional de Conservación del Patrimonio Cultural (CNCPC) del INAH durante 2011, recibió, ante semejante hallazgo, una relevante experiencia en materia de interpretación y conservación arqueológicas desde una perspectiva de colaboración interdisciplinaria.
\end{abstract}

\section{Antecedentes arqueológicos y relevancia de los artefactos}

El sitio Teteles de Santo Nombre se ubica al suroeste de Tlacotepec de Benito Juárez, entre las poblaciones de Xochitlán Todos Santos y Santa María Alta, en el estado de Puebla, México. Sus coordenadas geográficas son $18^{\circ} 37^{\prime} 40^{\prime \prime} \mathrm{N}$ y $97^{\circ} 42^{\prime} 59^{\prime \prime}$ w con altitud de 1950 msnm (Figura 1).

Durante las exploraciones en el sitio, realizadas en temporadas de 2009 a 2011, se excavaron aproximadamente 62 ha de los ejidos de Santo Nombre y San Lucas Palmillas.

Las estructuras de la zona comprenden un periodo que va del Preclásico tardío al Clásico medio, entre 200 a.C. y 600 d.C. A la fecha, los espacios liberados mediante la excavación indican que los edificios se clausuraron intencionalmente entre 550 y 600 d.C. (Castellón Huerta 2009). El contexto 


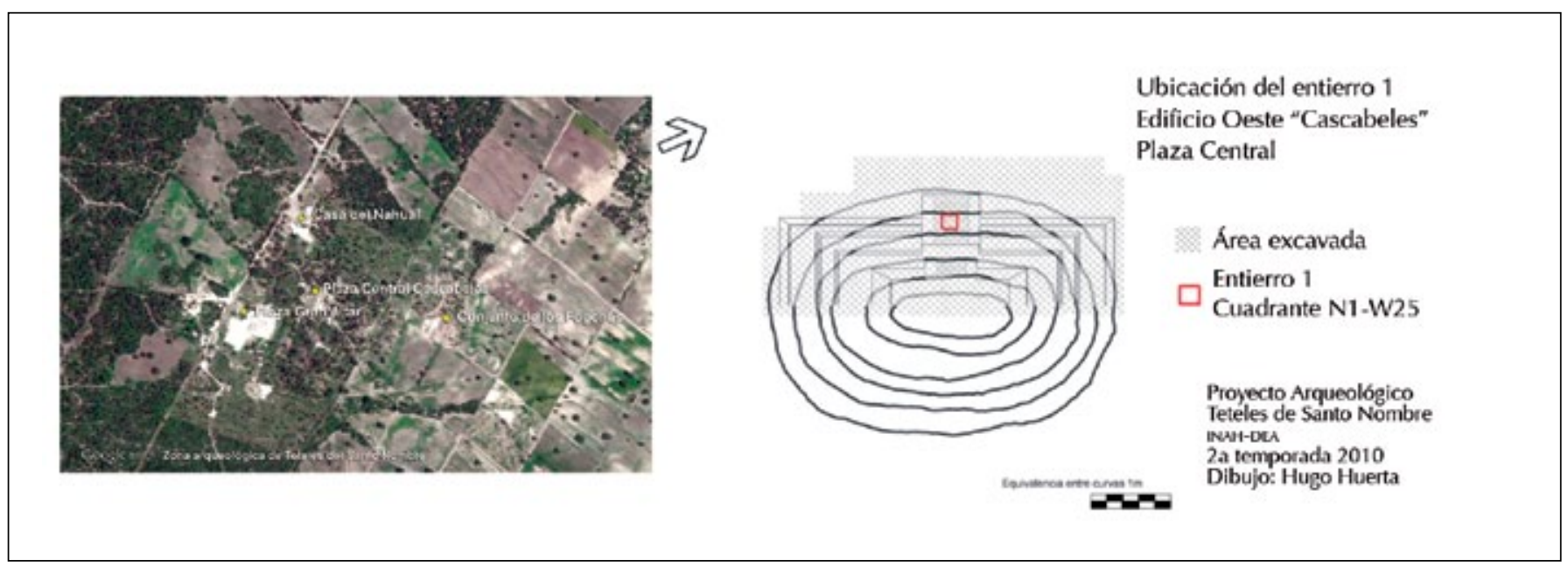

FIGURA 1. Ubicación geográfica del sitio arqueológico Teteles de Santo Nombre, municipio de Tlacotepec de Benito Juárez, Puebla, México (Fotografía: Google Earth 2011, tomada en el 2012), y vista del complejo funerario descubierto en la escalinata de la estructura Cascabeles, sitio arqueológico Teteles de Santo Nombre (Fotografía: Hugo A. Huerto Vicente, 2011; cortesía: proyecto arqueológico Teteles de Santo Nombre, DEA-INAH).

funerario al que pertenecen las tobiIleras corresponde a la fachada poniente de la estructura denominada Cascabeles, ubicada al oeste de la plaza central. Debe destacarse que la evidencia arqueológica señala, tentativamente, que el entierro se dispuso sobre la escalinata del edificio en el Posclásico, momento posterior al de su ocupación, cuando el uso de metales fue más común (Hosler 1997), lo que hace suponer que el sitio mantuvo una importancia simbólico-ritual aún después de su abandono (Castellón Huerta 2009).

El entierro, de tipo primario-directo, corresponde al de un individuojuvenil con un parámetro de 12 a 15 años de edad, a quien se sepultó en una posición sedente flexionada, con la cabeza y el cuerpo orientados al norte y al oeste, respectivamente. Sobre la palma de su mano izquierda se encontraron pequeños huesos de aves incompletos, de los cuales se identificaron dos especies: una codorniz arlequín: Cyrtonyx montezumae, y un gavilán pechiblanco: Accipiter chionogaster (Castellón Huerta 2011). A la altura del esternón se encontró una cuenta perforada de piedra verde, la cual sólo pudo haber llegado ahí a través de la cavidad bucal; es decir, el individuo tragó la cuenta, o bien le fue inducida. Sobre ambos tobillos se encontraron los cascabeles y materiales orgánicos en cuestión (Figura 2).

De acuerdo con Dora M. K. de Grinberg (1993: 17), "el estudio de la metalurgia nos ayuda a entender el desarrollo cultural de un grupo humano, ya que para producir objetos metálicos es necesario contar con los cimientos de otros conocimientos previos". Con base en esto es posible determinar la relevancia de los artefactos arqueológicos que aquí nos ocupan, ya que hablan del desarrollo de la producción, el uso y el sig-
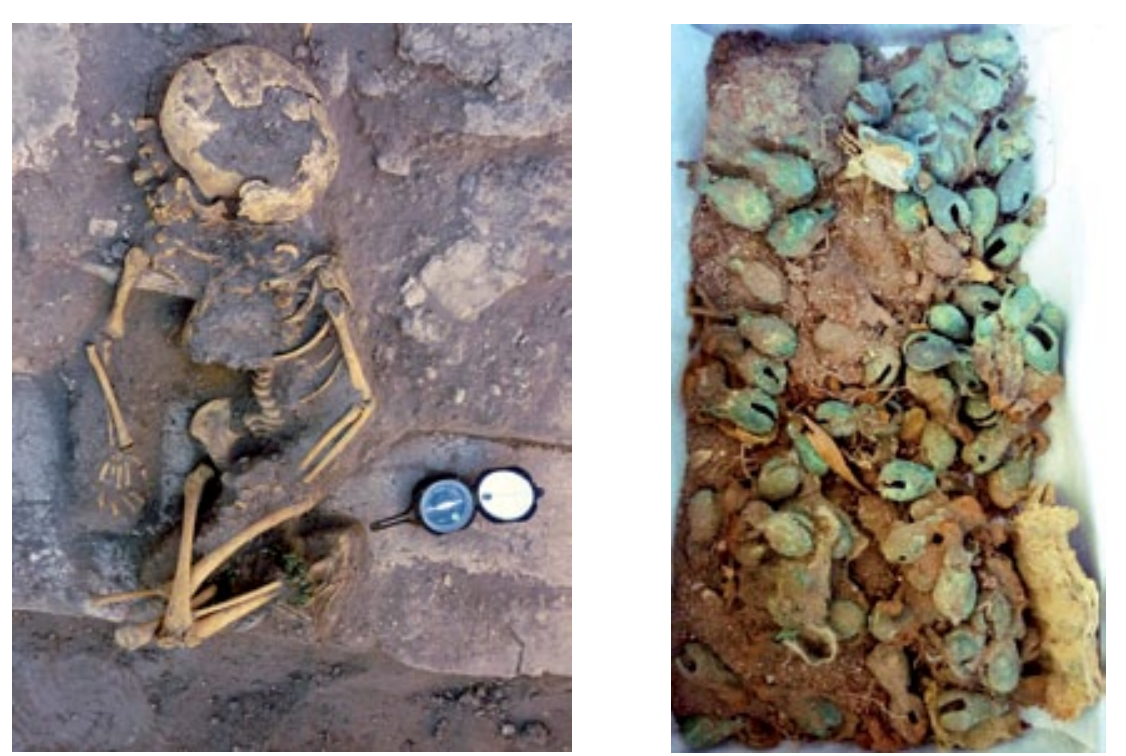

FIGURA 2. Aspecto del entierro en el edificio Cascabeles y de las Tobilleras después de su excavación (Fotografía: Hilda P. Salgado Serafín, 2010; cortesía: proyecto arqueológico

Teteles de Santo Nombre, DEA-INAH).

nificado del trabajo en metales en la América precolombina. Según Juan Méndez Vivar (2004: 11), la metalurgia mesoamericana tuvo un enfoque más bien ornamental —a diferencia de aquel utilitario del Viejo Continente-, particularmente en el periodo Posclásico, entre los años 600 a 800 D.C. (Hosler 1997). No fue sino hasta 1200 o 1300 D.C. cuando se empezaron a utilizar aleaciones de cobre para optimizar el diseño y la funcionalidad de objetos con significados rituales. 
Los cascabeles (o coyolli, en voz náhuatl) son ejemplo de este tipo de objetos (Méndez Vivar 2004: 11) que es posible apreciar representados en varios códices precolombinos datados para el Posclásico y de adscripción nahua, entre ellos el Magliabechi, el Vaticano y el Ixtlilxochitl, en los que dioses, nobles y guerreros portan estos adornos en brazos, piernas y torso (Schulze 2008: 203). El uso de cascabeles se ha encontrado, además de en los atavíos, en contextos mortuorios (Schulze 2008: 204). Se conocen otros entierros de infantes asociados con cascabeles atados a las piernas, como es el caso de la ofrenda 111 del Templo Mayor (Schulze 2008: 22). Schulze (2008: 203) menciona que a pesar de que existe una gran cantidad de ejemplos de personajes portando cascabeles, se conservan muy pocos de éstos conectados a una tira de material textil o piel. Tomando en cuenta lo anterior, podemos determinar que las tobilleras en estudio son piezas únicas en el
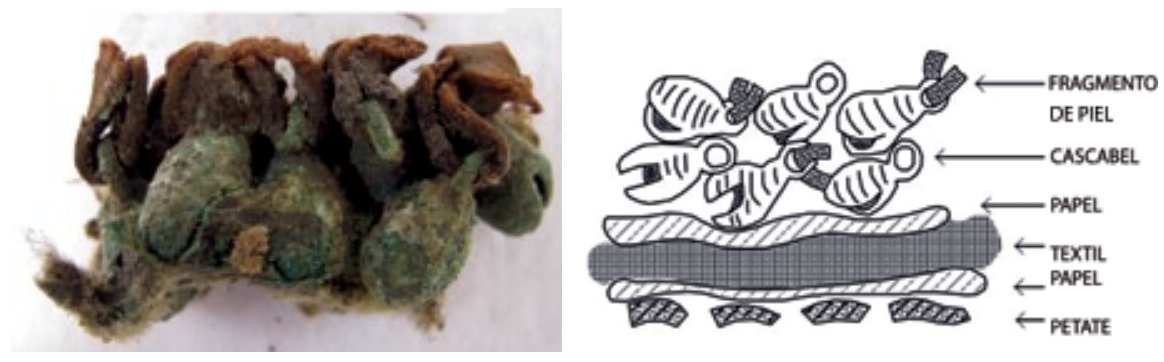

FIGURA 3. Esquema y foto de estratigrafía del complejo arqueológico (Registro: Fabiana González Portoni; digitalización: Mariana Aguirre; fotografía: Diana Carmona Loaiza, 2011; cortesía: CNCPC-INAH)

repertorio arqueológico de la región centro-oriental de Mesoamérica, y que su sofisticación radica en que combinan cascabeles hechos de una aleación de cobre con diversos elementos orgánicos —incluso textiles y piel一, condición determinante en la complejidad de su estado material postexcavación (Figura 3).

\section{Intervención}

La intervención comprendió cinco fases: registro; identificación de ma- teriales constitutivos; diagnóstico y propuesta; conservación, restauración y montaje, cuyas particularidades se detallan en seguida.

\section{Registro}

La realización de un registro detallado de todos los elementos presentes en la pieza fue un proceso fundamental, que se explica en la siguiente tabla (Figura 4), para recobrar su integridad en la medida de lo posible:

\begin{tabular}{|c|c|c|}
\hline \multicolumn{3}{|c|}{ REGISTRO DE ELEMENTOS } \\
\hline MATERIAL & OBSERVACIONES & SISTEMA DE REGISTRO \\
\hline $\begin{array}{l}\text { Fragmentos } \\
\text { de piel }\end{array}$ & $\begin{array}{l}\text { Situados dentro de los arillos de los cascabeles. } \\
\text { Probablemente se trataba de una tira completa de piel con } \\
\text { la que, uno a uno, los cascabeles se sujetaron a la banda } \\
\text { de soporte, la cual actualmente se presenta fragmentada } \\
\text { en cada uno de los dobleces. }\end{array}$ & $\begin{array}{l}\text { Los elementos de piel se separaron mecánicamente } \\
\text { de los arillos con ayuda de pinzas, y se guardaron } \\
\text { con el mismo número del cascabel con el que se } \\
\text { encontraron para ser reintegrados a su posición inicial } \\
\text { una vez intervenidos. }\end{array}$ \\
\hline Cascabeles & $\begin{array}{c}69 \text { cascabeles de tipo periforme* con } \\
\text { dimensiones promedio de } 1.5 \mathrm{~cm} \text { de alto por } \\
0.9 \mathrm{~cm} \text { de ancho. Se encontraban distribuidos } \\
\text { en dos filas. }\end{array}$ & $\begin{array}{c}\text { Ya que los materiales venían en cúmulos, y, por lo tanto, } \\
\text { era imposible determinar a simple vista la cantidad } \\
\text { de cascabeles presentes, se realizaron radiografías para } \\
\text { establecer su número total. }\end{array}$ \\
\hline Papel & \multirow{3}{*}{$\begin{array}{l}13 \text { fragmentos de material orgánico: } 5 \text { de papel, } \\
6 \text { de textil y } 2 \text { de papel con textil. }\end{array}$} & \multirow{3}{*}{$\begin{array}{c}\text { Con la finalidad de mantener la relación de todas } \\
\text { las capas y elementos, se realizaron esquemas de los } \\
\text { fragmentos de textil y papel que estuvieran asociados } \\
\text { con cascabeles, representando el estado de } \\
\text { conservación y localización de cada uno de ellos. }\end{array}$} \\
\hline Textil & & \\
\hline Papel con textil & & \\
\hline Petate & $\begin{array}{l}\text { Restos de petate de palma asociados con los fragmen- } \\
\text { tos de papel-textil-papel; al reverso de uno de los } \\
\text { fragmentos de papel se identificaron improntas del } \\
\text { tejido del petate de tipo tafetán (1:1), lo que hace } \\
\text { pensar que podría tratarse de una capa que estuvo en } \\
\text { contacto con la piel del individuo. }\end{array}$ & $\begin{array}{l}\text { No se realizó un registro; los restos únicamente } \\
\text { se separaron de la tierra de contexto y se embalaron. }\end{array}$ \\
\hline
\end{tabular}

FIGURA 4. Tabla de registro de elementos constitutivos de las tobilleras de Teteles de Santo Nombre. 


\section{Identificación de materiales constitutivos}

Con el fin de lograr una intervención de restauración fundamentada, previa a cualquier tratamiento, se identificaron los materiales constitutivos de la pieza (Figura 5).

\section{Diagnóstico y propuesta}

Gracias a las observaciones realizadas y a la consulta con especialistas, se estableció un diagnóstico general sobre el estado material de cada una de las piezas para, así, crear una propuesta de intervención adecuada.

En general, los materiales orgánicos, si bien las fibras vegetales se encontraban rígidas y con cierta resequedad, presentaban una estabilidad relativa: es un hecho que la capacidad bactericida del cobre promovió la conservación de estos materiales orgánicos, difícilmente encontrados en contextos arqueológicos. Los fragmentos de piel, por su parte, estaban rígidos y secos a causa de falta de agua, lo cual, evidentemente, hizo que este material se conservara: al desecarse se hace resistente al ataque de hongos, bacterias e hidrólisis (Kite y Thomson 2006:279).

Por su lado, los cascabeles, pese a que sí presentaban una corrosión activa - muestra de esto son los productos de corrosión presentes en superficie, como la cuprita, la malaquita, la cerusita, entre otros-,

\begin{tabular}{|c|c|c|c|c|}
\hline \multicolumn{5}{|c|}{ IDENTIFICACIÓN DE MATERIALES CONSTITUTIVOS } \\
\hline MATERIAL & $\begin{array}{l}\text { TÉCNICA } \\
\text { EMPLEADA }\end{array}$ & $\begin{array}{c}\text { REALIZÓ } \\
\text { EL ESTUDIO }\end{array}$ & RESULTADOS & OBSERVACIONES \\
\hline \multirow{3}{*}{ Metales } & Radiografía & $\begin{array}{l}\text { Radiólogo Federico } \\
\text { Gallardo (servicios } \\
\text { particulares). }\end{array}$ & $\begin{array}{l}\text { Se determinó la cantidad de } \\
\text { núcleo metálico sano vs. } \\
\text { proporción de corrosión }\end{array}$ & $\begin{array}{l}\text { La proporción guardada entre metal sano } \\
\text { y corrosión es variable en cada cascabel, por lo } \\
\text { cual cada uno requiere de un tratamiento } \\
\text { particular. Se observó que sólo } 4 \% \text { de la colección } \\
\text { presentaba picaduras en el metal }\end{array}$ \\
\hline & \multirow[t]{2}{*}{$\begin{array}{l}\text { Fluorescencia } \\
\text { de Rayos X }\end{array}$} & $\begin{array}{c}\text { Dr. José Luis Ruvalcaba } \\
\text { (IF, UNAM), con asesoría } \\
\text { de Mtra. Pilar Tapia, Lic. } \\
\text { Gabriela Peñuelas } \\
\text { y Lic. Ingrid Jiménez } \\
\text { (STRM, ENCRyM-INAH) }\end{array}$ & \multirow[t]{2}{*}{$\begin{array}{l}\text { Aleación de cobre, plomo } \\
\text { y arsénico }(\mathrm{Cu}-\mathrm{Pb}-\mathrm{As}) \text {. Si bien } \\
\text { las cantidades de los metales } \\
\text { varían ligeramente, siempre } \\
\text { predomina el cobre }\end{array}$} & \multirow{2}{*}{$\begin{array}{l}\text { Al comparar esta aleación con información del } \\
\text { banco de resultados en aleaciones de cascabeles } \\
\text { prehispánicos realizado por el Dr. Ruvalcaba, se } \\
\text { determinó que este tipo de aleación es común en } \\
\text { los cascabeles periformes mesoamericanos } \\
\text { encontrados en la cuenca de México. }\end{array}$} \\
\hline & & $\begin{array}{l}\text { Quím. Javier Vázquez } \\
\text { (Laboratorio de } \\
\text { Investigación- ENCRyM- } \\
\text { INAH) }\end{array}$ & & \\
\hline $\begin{array}{l}\text { Fibras } \\
\text { textiles }\end{array}$ & $\begin{array}{l}\text { Observación } \\
\text { con } \\
\text { microscopio } \\
\text { estereoscópico }\end{array}$ & $\begin{array}{l}\text { M. en C. Alejandro } \\
\text { Medina (CNCPC-INAH) y } \\
\text { Mtra. Gabriela Cruz } \\
\text { (ENCRyM-INAH) }\end{array}$ & Fibras de algodón & Tejido de tafetán sencillo. \\
\hline Fibras duras & $\begin{array}{l}\text { Observación } \\
\text { con } \\
\text { microscopio }\end{array}$ & $\begin{array}{l}\text { Mtra. Gabriela Cruz y } \\
\text { Biól. Iraís Velasco } \\
\text { (ENCRyM-INAH) }\end{array}$ & $\begin{array}{l}\text { Palma de la familia } \\
\text { Arecaceae }\end{array}$ & $\begin{array}{l}\text { La identificación se dio al comparar } \\
\text { características de la fibra con una base de datos } \\
\text { de fibras naturales mexicanas. }\end{array}$ \\
\hline Papel & $\begin{array}{l}\text { Observación } \\
\text { con } \\
\text { microscopio } \\
\text { óptico }\end{array}$ & $\begin{array}{l}\text { Lic. Marie Vandeer } \\
\text { (CNCPC-INAH) }\end{array}$ & Papel amate & $\begin{array}{c}\text { En un objeto ornamental, el uso de papel como } \\
\text { material de soporte junto con textiles es algo } \\
\text { inusual y de lo que no se tiene sino escasa } \\
\text { información. }\end{array}$ \\
\hline \multirow[t]{2}{*}{ Piel } & $\begin{array}{l}\text { Observación } \\
\text { con microsco- } \\
\text { pio óptico y } \\
\text { microscopio } \\
\text { electrónico de } \\
\text { barrido }\end{array}$ & $\begin{array}{l}\text { Mtra. Gabriela Cruz, } \\
\text { Biól. Iraís Velasco y } \\
\text { especialista en pieles } \\
\text { Luis Enríquez Vázquez } \\
\quad \text { (ENCRyM-INAH) }\end{array}$ & $\begin{array}{l}\text { Piel con un tratamiento similar } \\
\text { al de la gamuza* }\end{array}$ & $\begin{array}{l}\text { Debido al deterioro de los fragmentos de piel y a } \\
\text { la posibilidad de que se trate de algún animal } \\
\text { endémico de Mesoamérica, como el venado, no } \\
\text { fue posible establecer claramente el tipo de } \\
\text { animal del que se extrajeron. }\end{array}$ \\
\hline & $\begin{array}{l}\text { Determinación } \\
\text { de } \mathrm{pH}\end{array}$ & $\begin{array}{l}\text { Lic. Fabiana } \\
\text { González Portoni } \\
\text { (ENCRyM-INAH) }\end{array}$ & $\mathrm{pH}: 5$ & $\begin{array}{l}\text { De acuerdo con conservadores expertos en piel, } \\
\text { como Marion Kite y Roy Thomson (2006: 84-85), } \\
\text { las pieles con pH } 3.2 \text { o más pueden } \\
\text { considerarse estables. }\end{array}$ \\
\hline & COn do & a a partir de descarnes de & $\begin{array}{l}\text { piel, usualmente, ovina (imposible er } \\
\text { raspado, curtida por un proceso que } \\
\text { os), o bien por curtición combinada ( } \\
\text { te y Thomson 2006: } 274,276 \text { ). }\end{array}$ & $\begin{array}{l}\text { este caso, debido a que no había presencia de ganado } \\
\text { oxida la piel con aceites, ya sea solos (curtición pura } \\
\text { on empleo, asimismo, de curtientes sintéticos) }\end{array}$ \\
\hline
\end{tabular}

FIGURA 5. Tabla de identificación de materiales constitutivos de las tobilleras de Teteles de Santo Nombre. 
contaban con suficiente núcleo metálico sano como para calificar de bueno su estado material, y aún considerar someterlos a una limpieza mecánica y química para retirar los productos de corrosión.

Aunque es innegable que se ha perdido una parte significativa de los objetos, el material que se conservó alcanza a dar cuenta de aspectos trascendentes, tales como la recreación de la técnica de manufactura, su uso y, relacionando al objeto con las observaciones realizadas en el proceso de registro y con los datos contextuales, la hipótesis sobre su significado cultural y ritual.

Para intervenir fundadamente una pieza arqueológica tan peculiar co- mo la mencionada en este reporte fue necesario tomar en cuenta tres conceptos: integridad, unicidad y autenticidad, cuyo contraste con la información adquirida en la investigación nos ayudaría a establecer criterios de intervención a seguir.

En lo que respecta al primer concepto, el proceso de registro ofreció datos que permitían interpretar el artefacto y recrearlo como un todo, pese a que estaba fragmentado. Por ello la intervención se dirigió a restablecer la posibilidad de que un espectador "imaginara" el artefacto íntegro antes de su incorporación al ajuar funerario. Al potenciar la comprensión de su significado, se cumplió con un requerimiento teórico que desde los inicios de la disciplina de la restauración se ha considerado de primordial importancia (Brandi 1977: 23-28).

Por su parte, el concepto de unici$\mathrm{dad}$, que se refiere a la característica que confiere al patrimonio cultural su calidad de bien único e irrepetible, estableció otra norma que rigió la intervención de las tobilleras: respetar al máximo sus características, valga la redundancia, únicas e irrepetibles, que le otorgan un valor como pieza excepcional en el acervo arqueológico mesoamericano, principalmente en cuanto a diversidad de materiales incorporados en su compleja manufactura.

Las reflexiones anteriores nos Ilevaron a planear la intervención como

\begin{tabular}{|c|c|c|c|c|}
\hline MATERIAL & PROCESO & TÉCNICA & MÉTODO & OBSERVACIONES \\
\hline \multirow{4}{*}{ Cascabeles } & \multirow{2}{*}{$\begin{array}{l}\text { Eliminación de } \\
\text { suciedad y productos } \\
\text { de corrosión }\end{array}$} & $\begin{array}{l}\text { Brocha de pelo } \\
\text { suave }\end{array}$ & $\begin{array}{c}\text { Remoción mecánica } \\
\text { de polvo y tierra superficiales. }\end{array}$ & \\
\hline & & $\begin{array}{l}\text { Tartrato de sodio } \\
\text { y potasio (sales } \\
\text { de Rochelle) al } 5 \% \\
\text { en agua }\end{array}$ & $\begin{array}{l}\text { Limpieza físico-química por } \\
\text { inmersión en la solución, } \\
\text { o mediante cepillado con pincel } \\
\text { de cerdas de nylon. }\end{array}$ & $\begin{array}{l}\text { Procedimiento convencional para } \\
\text { la conservación de metales.* }\end{array}$ \\
\hline & Pasivación & $\begin{array}{l}\text { Benzotriazol al } \\
1 \% \text { en alcohol }\end{array}$ & $\begin{array}{l}\text { Los cascabeles se calentaron en una } \\
\text { platina y se sumergieron en la } \\
\text { solución durante } 15 \text { minutos. }\end{array}$ & $\begin{array}{l}\text { Este tratamiento se ha explorado } \\
\text { ampliamente en la conservación } \\
\text { de metales. }{ }^{* *}\end{array}$ \\
\hline & $\begin{array}{l}\text { Capa de } \\
\text { protección }\end{array}$ & $\begin{array}{l}\text { Paraloid } \mathrm{B} 75^{\circledR} \text { al } 5 \% \\
\text { en acetona }\end{array}$ & Inmersión durante 30 minutos. & \\
\hline \multirow{2}{*}{$\begin{array}{c}\text { Fibras } \\
\text { textiles y } \\
\text { papel amate }\end{array}$} & $\begin{array}{l}\text { Eliminación de } \\
\text { suciedad superficial }\end{array}$ & Aspiradora & $\begin{array}{l}\text { Aspirado puntual con } \\
\text { barrera de malla Monyl}{ }^{\circledR} \text {. }\end{array}$ & \\
\hline & $\begin{array}{l}\text { Estabilización } \\
\text { material }\end{array}$ & $\begin{array}{l}\text { Methocel }^{\circledR}(25 \%), \\
\text { almidón de arroz } \\
\text { (25\%) y polietilenglicol } \\
200(50 \%) \text { (Miranda } \\
\text { y Sánchez 1996) }\end{array}$ & $\begin{array}{l}\text { Los fragmentos se sumergieron } \\
\text { durante un periodo de } 10 \text { a } 15 \\
\text { minutos. }\end{array}$ & $\begin{array}{c}\text { Proceso encaminado a recuperar } \\
\text { la estabilidad material, regresando } \\
\text { cohesión y flexibilidad a las fibras. }{ }^{* * *}\end{array}$ \\
\hline Piel & $\begin{array}{l}\text { Eliminación } \\
\text { de suciedad }\end{array}$ & Brocha de pelo suave & Eliminación mecánica suave. & $\begin{array}{l}\text { No se realizaron procesos de } \\
\text { restauración a los fragmentos de piel, ya } \\
\text { que éstos se encontraban estables } \\
\text { y no representan un peligro para la } \\
\text { conservación de los demás materiales. }\end{array}$ \\
\hline $\begin{array}{r}{ }^{*} \mathrm{EI} \\
\text { o co } \\
{ }^{* *} \text { El benzc } \\
{ }^{* * *} \mathrm{Tr}\end{array}$ & $\begin{array}{l}\text { trato de sodio y potasio } \\
\text { ouestos estables, cuya for } \\
\text { el contacto del hier } \\
\text { iazol es un agente quelan } \\
\text { de que es cap } \\
\text { amiento planteado por las }\end{array}$ & $\begin{array}{l}\text { s un agente quelante que fo } \\
\text { mación impide que los iones } \\
\text { o con el oxígeno o el agua } \\
\text { te que captura iones de cob } \\
\text { az de crear una capa establ } \\
\text { restauradoras Miranda y Sa } \\
\text { con muy buenos resultado }\end{array}$ & $\begin{array}{l}\text { rma enlaces covalentes coordinados con ior } \\
\text { metálicos reaccionen con los demás eleme } \\
\text { e evita que se generen productos de corros } \\
\text { e (Cu): evita la interacción del metal con e } \\
\text { que protege la superficie del metal (Sease } \\
\text { nchez (1996) para intervenir textiles arque } \\
\text { en el taller de textiles de la CNCPC-INAH. }\end{array}$ & $\begin{array}{l}\text { es metálicos y forma quelatos, } \\
\text { tos que los rodean. Al impedir } \\
\text { ón (Burgess 1991). } \\
\text { medio e inhibe la corrosión, además } \\
\text { 978:76-77). } \\
\text { lógicos. Se utiliza hasta la fecha }\end{array}$ \\
\hline
\end{tabular}

FIGURA 6. Tabla de tratamientos de conservación y restauración realizados. 
un proceso que enfrentaría dos retos. El primero, preservar, y aún optimizar, esa relativa estabilidad que habían mantenido tanto los cascabeles como el material orgánico. Luego, presentar la pieza de modo que fuera posible observar e interpretar el objeto en su carácter unitario e íntegro (ya que mostrar los materiales de manera separada no era una solución viable, pues no se entendería la función original del artefacto).

De ahí que desde un inicio se planteara estabilizar los diversos materiales de manera individual para, posteriormente, colocarlos en un montaje con materiales estables que permitieran la lectura de las tobilleras como un todo. Para esto fue necesario remontarse al tercer concepto, de autenticidad, que, en el caso de las tobilleras, se conservó durante su intervención manteniendo tanto al artefacto individual como a su contexto, determinado por la organización y la interacción de sus diversos materiales —esta última, condición que hacía al hallazgo tan peculiarlo más cercano posible a la manera en que se encontraron en el entierro.

\section{Conservación y restauración}

En la tabla de la Figura 6 se sintetizan los tratamientos de conservación y restauración realizados a cada uno de los cuatro grupos de materiales.

\section{Montaje}

Los datos arqueológicos indicaban que se había colocado una banda en cada uno de los tobillos de un individuo de entre 12 y 15 años. La medida promedio del grosor del tobillo de un joven de esa edad es de $19 \mathrm{~cm}$. Además, al disponer los 69 cascabeles en hileras paralelas, se obtenía un largo aproximado de $40 \mathrm{~cm}$, lo que concuerda con la idea de tener dos tobilleras de $20 \mathrm{~cm}$ cada una. Con base en esta línea se decidió hacer un montaje que recreara dos bandas (Figura 7).

En la construcción original de las tobilleras, los cascabeles estaban

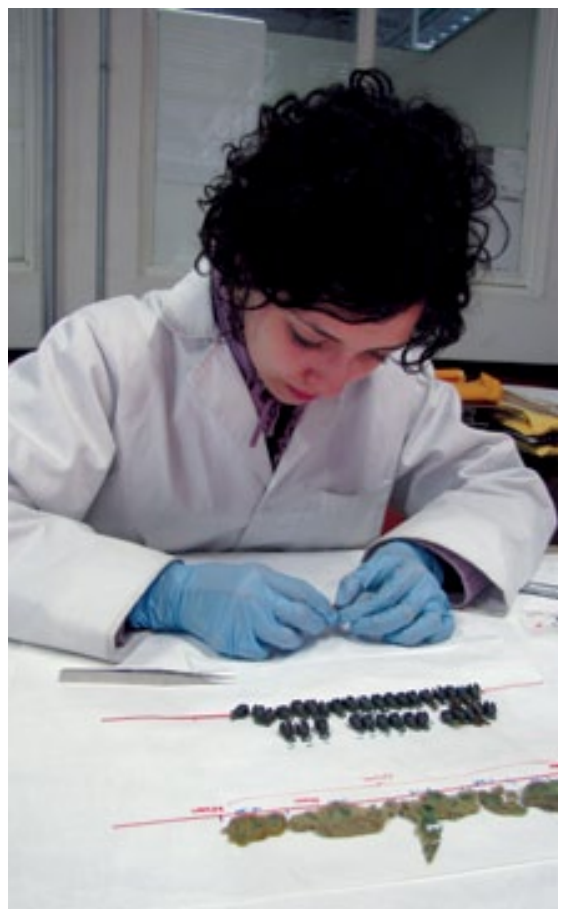

FIGURA 7. Pruebas de montaje (Fotografía: Diana Carmona Loaiza, 2011; cortesía: CNCPC-INAH).

montados sobre una banda de tela recubierta por papel, atados uno a uno por medio de una tira de cuero. Por motivos de conservación y para mantener la estabilidad de los diferentes materiales, se decidió montarlos de manera separada, lo cual, sin embargo, significaría perder la unidad del objeto y poner en riesgo la comprensión de su uso y función, factores que en las primeras etapas de la intervención se detectaron como trascendentes y dignos de conservar. Por lo anterior se decidió recurrir a una herramienta muy socorrida en el dibujo, la arquitectura y el diseño: "los objetos en vista explotada". ${ }^{1}$ La diseñadora industrial Lorena Ahuactzin (CNCPC-INAH) ideó dos soportes de acrílico (uno para cada tobillo) con tres niveles, en los que colocó, respectivamente, la primera y la segunda tiras de cascabeles, y el textil y el papel, y unió todos estos elementos

\footnotetext{
${ }^{1}$ Técnica que presenta un objeto separado de todas sus partes pero guardando una relación espacial por capas, por lo que permite, a la vez que se brinda la idea de un todo, entender cada uno de los elementos por separado.
}

por medio de costura. El observador tiene ante sí, por la transparencia del acrílico, las tobilleras en vista cenital, y las aprecia como un todo. Si uno se coloca frente al montaje, entonces entiende cabalmente la manufactura en capas de la tobillera y, a la vez, reconoce cada elemento individualmente.

Por último, los dos soportes se colocaron dentro de una vitrina, también de acrílico, en la cual se creó un espacio oculto para albergar una charola que contiene Silicagel ${ }^{\circledR 2}$ (Figura 8).

\section{Conclusiones}

Como mencionan Alonso y García (2002:39), "la conservación debe ser una herramienta para la interpretación arqueológica y debe contribuir a preservar al conjunto de los bienes arqueológicos de manera íntegra...". Durante la restauración y la conservación de estas tobilleras, se realizó el análisis - con el consecuente entendimiento- de los diferentes materiales para, de esta forma, lograr tanto la estabilización del objeto como su interpretación.

Las tobilleras Ilegaron a la CNCPCINAH Como un conjunto de materiales imbricados; sin embargo, debido a su contexto: objetos provenientes de un entierro, no era clara esta relación. Gracias al registro, la intervención y la información obtenida de los diversos estudios y análisis, fue posible hacer una interpretación que recreara la técnica de manufactura del objeto $y$, con eso, formular una hipótesis sobre su uso, función e, incluso, significado, factores que se observan y materializan en la restauración, la conservación y el sistema de montaje elegidos.

Por su naturaleza arqueológica, se decidió dar más peso — si bien no se descartó su estética y funcionalidad, que también tuvieron un papel importante durante la toma de decisiones - a la instancia histórica y

\footnotetext{
${ }^{2}$ Material que permitirá mantener una humedad relativa baja dentro de la vitrina.
} 

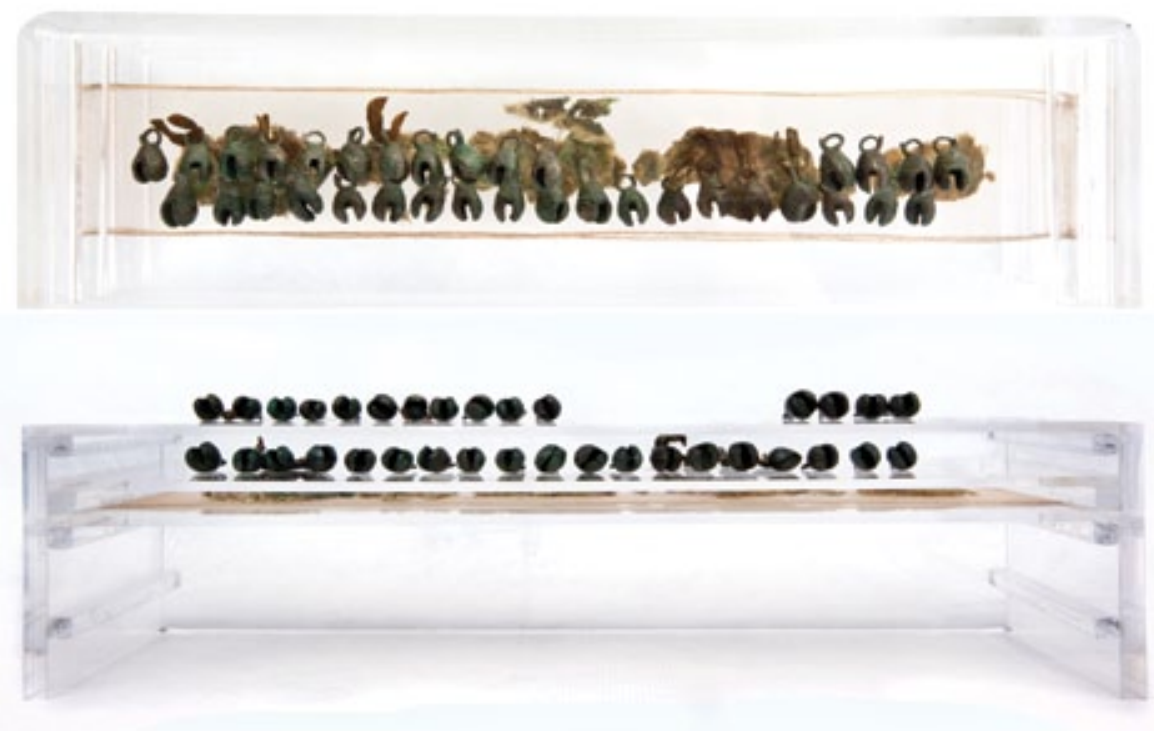

FIGURA 8. Aspecto de las tobilleras al final de su conservación, restauración y montaje (Fotografía: ${ }^{\circ} J o s e p h$ Bolt, 2012; cortesía: CNCPC-INAH).

discursiva de la pieza. Es innegable que la capacidad del objeto para ser leído como evidencia arqueológica fue lo que orientó la mayoría de las decisiones durante su restauración. Las tobilleras son un claro ejemplo de una serie de manifestaciones artísticas que vinculan a las personas con su pasado $y$, como mencionan Mason y Avrami (2000: 16), "brindan un contacto físico con estas épocas previas". Es justamente este "contacto" el que se persiguió a lo largo de esta intervención y montaje.

\section{Referencias}

Alonso Olvera, Alejandra y Valeria García Vierna

2002 "Lineamientos teóricos y prácticos para la conservación arqueológica: una propuesta para la Subdirección de Conservación del Patrimonio Cultural del INAH", mecanoescrito, México, CNCPC-INAH.

Álvarez, Jacinto et al.

2009 "Informe de los trabajos de restauración realizados a cascabeles provenientes de Templo Mayor", mecanoescrito, México, ENCRYM-INAH.

Brandi, Cesare

1996 Teoría de la restauración, Madrid, Alianza. publicacionesbanrep/bolmuseo/1997/ enjn42/enjn01a.htm], consultado en octubre de 2011.

Kite, Marion y Roy Thomson 2006 Conservation of Leather and Related Materials, Oxford, ButterworthHeinemann.

Mason, Randall y Erica Avirami 2000 "Heritage values and challenges of Conservation planning", en Gaetano Palumbo y Jeanne Marie Teutonico (eds.), Management Planning to Archeological Sites, Los Ángeles, The Getty Conservation Institute, 13-26.

Méndez Vivar, Juan

2011 Los minerales en la época prehispánica, documento electrónico disponible en [http://www.izt.uam.mx/contactos/n43ne/minerales.pdf], consultado en octubre de 2011.

Miranda Ham, Susana y Gloria Martha Sánchez Valenzuela

1996 "Conservación de textiles y cordelería prehispánica, cuevas 'El Gallo' y 'La Chaguera', Ticuman, Morelos", tesis de licenciatura en Restauración de Bienes Muebles, México, ENCRyMINAH.

Özen, Latif y Krysia Spirydowicz

2002 Conservation of Leather \& Textile Artifacts on Archaeological Sites (Field Notes 17), documento electrónico disponible en [http://www.jiaakaman.org/images/fn/pdf/fieldnotes_ no_17.pdf], consultado en noviembre de 2011.

Pendergast, David M.

1962 "Metal artifacts in Prehispanic Mesoamerica", American Antiquity, 27 (4): 520-545.

Schulze, Niklas

2008 "El proceso de producción metalúrgica en su contexto cultural: los cascabeles de cobre del Templo Mayor de Tenochtitlan", tesis de doctorado en Antropología, México, IIA-UNAM.

Sease, Catherine

1978 "Benzotriazole: A review for Conservators", Studies in Conservation 23 (2): 76-85.

Tapia López, María del Pilar 1999 "Limpieza de cobre y bronce arqueológicos, cascabeles del Templo Mayor", tesis de licenciatura en Restauración de Bienes Muebles, México, ENCRYM-INAH. 
Tetréault, Jean

1994 Display Materials, The Good, The Bad and The Ugly, $\mathrm{CCl}$, documento electrónico disponible en

[http://www.cciicc.gc.ca/publications/cidb/view-

\section{Resumen}

El descubrimiento de unas tobilleras con cascabeles de cobre en el sitio arqueológico Teteles de Santo Nombre, en Puebla, México, no sólo ofreció la oportunidad de profundizar nuestro conocimiento sobre el uso de diversos materiales para la manufactura de objetos ornamentales en el Posclásico mesoamericano, sino que también representó un reto interesante para la conservación arqueológica. En este reporte se presentan los fundametnos y acciones mediante los cuales se realizó un registro detallado de cada uno de los estratos conformadores de las tobilleras en el depósito arqueológico, seguido de la exposición de los criterios e intervenciones dirigidos para su restauración, que condujeron, finalmente, a realizar una propuesta de exhibición integral que busca tanto preservar su materialidad como exponer su relevancia cultural

\section{Palabras clave}

Tobilleras, cascabeles de cobre, Teteles de Santo Nombre, conservación arqueológica.
document_e.aspx?Document_ID=83], consultado en enero de 2010.

Thomson, Garry

2005 The Museum Environment, Londres, Elsevier.

\section{Abstract}

The discovery of a couple of anklets made of copper bells in the archaeological site of Teteles de Santo Nombre, Puebla, Mexico, not only provided the opportunity to enhance our understanding regarding the diverse materials employed for making Post Classic Mesoamerican ornamental artefacts, but also became an interesting challenge for archaeological conservation. This article focuses on the principles and actions in which a detailed record of each of the strata conforming the anklets was made at the archaeological site. This was followed by an explanation of the criteria and interventions that were carried out for their conservation and restoration, an integral process that resulted in an exhibition that seeks both to preserve its materials and exhibit its cultural significance.

\section{Keywords}

Anklets, copper bells, Teteles de Santo Nombre, archaeological conservation

Título en inglés: Study, Conservation and Assembly of Two Copper Bell Anklets

from the Archaelogical Site Teteles de Santo Nombre in Puebla 